\title{
Patterns of Mandibular Third Molar Impaction in an Iranian Subpopulation
}

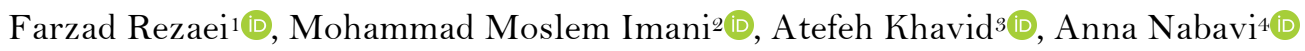

\begin{abstract}
${ }^{1}$ Department of Oral and Maxillofacial Surgery, Kermanshah University of Medical Sciences, Kermanshah, Iran. ${ }^{2}$ Department of Orthodontics, Kermanshah University of Medical Sciences, Kermanshah, Iran.

sDepartment of Oral and Maxillofacial Radiology, Kermanshah University of Medical Sciences, Kermanshah, Iran. ${ }^{4}$ Dentistry Research Committee, Kermanshah University of Medical Sciences, Kermanshah, Iran.
\end{abstract}

Author to whom correspondence should be addressed: Atefeh Khavid, Assistant Professor, Department of Oral and Maxillofacial Radiology, Kermanshah University of Medical Sciences, Kermanshah, Iran. Phone: +9891 88362065. E-mail: atefehkhavid@gmail.com.

Academic Editors: Alessandro Leite Cavalcanti and Wilton Wilney Nascimento Padilha

Received: 30 November 2019 / Accepted: 17 May 2020 / Published: 04 June 2020

How to cite this article: Rezaei F, Imani MM, Khavid A, Nabavi A. Patterns of mandibular third molar impaction in an Iranian subpopulation. Pesqui Bras Odontopediatria Clín Integr. 2020; 20:e5411. https://doi.org/10.1590/pboci.2020.099

\begin{abstract}
Objective: To assess the patterns of mandibular third molar impaction in an Iranian subpopulation. Material and Methods: This retrospective descriptive study evaluated 1000 panoramic radiographs retrieved from the archives of a private radiology clinic in Kermanshah city, Iran. Depth of impaction, position of impacted mandibular third molar relative to the mandibular ramus according to Pell and Gregory's classification and angle of impacted tooth according to Winter's classification were determined. Data were analyzed using the Chi-square and Wilcoxon tests. Results: Of 1000 radiographs, 230 (23\%) showed an impaction of at least one mandibular third molar. Mandibular third molar impaction was more common in females (60\%). Mesioangular (35.9\%) and vertical (34.8\%) impactions were the most common angles of impaction in the right and left sides, respectively. Level C (40.3\%) and Class I (63.7\%) were the most common types of impaction in terms of depth of impaction and position relative to ramus, respectively. No significant difference was observed between the right and left sides of the mandible in terms of patterns of mandibular third molar impaction $(\mathrm{p}>0.05)$. Conclusion: Mandibular third molar impaction was relatively common in the studied population. The mesioangular, level $\mathrm{C}$ and Class I impaction patterns were the most frequent.
\end{abstract}

Keywords: Surgery, Oral; Dentition, Permanent; Molar, Third; Tooth, Impacted. 


\section{Introduction}

Impaction of permanent teeth occurs as the result of inability of the tooth to erupt or presence of a barrier against the path of eruption [1]. Causes of tooth impaction include systemic and local factors. Systemic factors include certain nutritional habits, genetic impairments and malnutrition, while local factors include the size and position of the adjacent teeth, presence of compact bone covering the tooth, lengthy path of eruption and inadequate length of dental arch [2].

Impaction of mandibular third molars is the most common and has a prevalence of $27 \%$ to $68.6 \%$ [3]. Mandibular third molars have variable eruption times in different individuals and may erupt as early as 16 years of age or as late as 18 to 20 years of age. As the last teeth to erupt, mandibular third molars may not have adequate space in dental arch to erupt and this leads to their impaction. As a result, mandibular third molars have the highest frequency of impaction [4].

Mandibular third molar impaction often leads to complications such as pericoronitis, swelling, bone loss, resorption of the adjacent root, formation of cystic lesions or neoplasms [5]. It can also decrease the strength of the mandible and increase the risk of fracture of the angle of mandible, crowding of mandibular teeth, temporomandibular joint disorders, orofacial pain and neuralgia [3].

Impacted third molars have different patterns in terms of depth, position relative to the mandible and angle relative to the occlusal plane. Knowledge about these patterns is clinically important because some patterns of impacted third molars are associated with a higher risk of caries in the adjacent tooth [6], pain, pericoronitis [7] and fracture of the angle of mandible [8]. Moreover, it has been shown that type of third molar impaction affects the level of difficulty of its surgical removal [9] and occurrence of postoperative complications $[10,11]$. Thus, knowledge about the pattern of impaction of mandibular third molars in terms of depth of impaction, position relative to the mandibular ramus and angle can be used to assess the level of difficulty of their surgical extraction, and design the most efficient treatment plan with the lowest risk of complications [9].

Previous studies have shown variability in patterns of mandibular third molar impaction in different populations [12-14]. Considering the clinical significance of knowledge about the patterns of third molar impaction in different populations, this study aimed to assess the patterns of mandibular third molar impaction in patients residing in Kermanshah city, Iran.

\section{Material and Methods}

\section{Study Design}

This retrospective, descriptive, cross-sectional study evaluated 1000 panoramic radiographs retrieved from the archives of a private radiology clinic in Kermanshah city. The radiographs were selected by census sampling.

The inclusion criteria were good-quality panoramic radiographs of patients and availability of information regarding age and sex of patients. Radiographs of patients with a history of mandibular second molar or third molar extraction, maxillofacial anomalies and history of trauma to the maxillofacial region were excluded.

\section{Data Collection}

Demographic information regarding age and sex of patients and clinical information were collected in a checklist. Panoramic radiographs of patients were evaluated by a trained dentist under standard conditions. 
Intra-examiner reliability was calculated to be 1, which indicated excellent intra-examiner agreement. Third molars with complete roots but without functional occlusion were considered to be impacted. The pattern of impaction was determined based on the depth of impaction, position relative to the mandibular ramus and angle of impaction relative to the occlusal plane [1].

Depth of Impaction

Depth of impaction was defined as the relationship of cementoenamel junction (CEJ) of third molar relative to the bone crest according to the Pell and Gregory's classification [15], which was classified as follows: (A) CEJ above the bone crest; (B) Part of CEJ below the bone crest; and (C) Entire CEJ below the bone crest.

Position Relative to the Mandibular Ramus

Position relative to the mandibular ramus was determined as the position of the distal surface of the third molar crown relative to the anterior border of the ascending ramus using Pell and Gregory's classification [15]:

- Class I: Distal surface of molar tooth in front of the anterior border of ramus (ramus not covering the crown).

- Class II: Distal surface of molar tooth posterior to the anterior border of ramus (part of crown covered by the ramus).

- Class III: Distal surface of molar tooth posterior to the anterior border of ramus (complete crown coverage by the ramus).

Angle of Impaction

The angle of impaction was defined as the angle between the longitudinal axes of the second and third molars according to Winter's classification [16]: Vertical: -10 to $+10^{\circ}$; Mesioangular: 11 to $79^{\circ}$; Horizontal: 80 to $100^{\circ}$; Distoangular: -11 to $-79^{\circ}$; Buccolingual: Superimposition of crown and roots and Others: 111 to -80 (Figure 1).

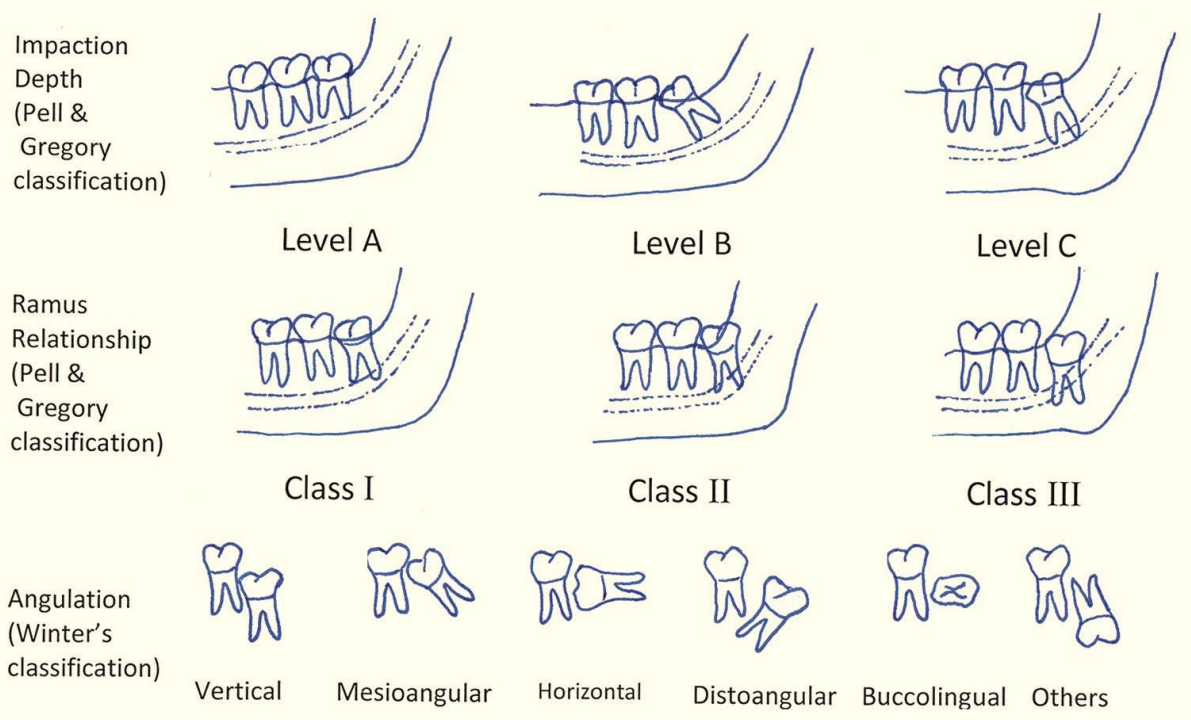

Figure 1. Classification of impacted mandibular third molars in terms of depth of impaction, position relative to the mandible and angle of impaction. 
Data Analysis

Data were analyzed using SPSS version 18 (SPSS Inc., IL, USA). The groups were compared using the Chi-square and Wilcoxon tests. $\mathrm{P}<0.05$ was considered statistically significant.

Ethical Considerations

All participants signed informed consent forms. The approval protocol number was IR.KUMS.REC.1396.733.

\section{Results}

A total of 1000 panoramic radiographs were evaluated, out of which 230 (23\%) showed unilateral or bilateral impaction of mandibular third molars, including 92 males (40\%) and 138 females (60\%). The mean age of patients was $32.8 \pm 8.3$ years (minimum 18 and maximum 58 years). The mean age was $33.1 \pm 9.1$ years (minimum 18 and maximum 58 years) in males and $32.6 \pm 7.8$ years (minimum 19 and maximum 58 years) in females. The difference in the mean age was not significant between males and females $(p=0.668)$.

Of 230 patients with mandibular third molar impaction, the impaction was in the right side in 72 (31.3\%), in the left side in $38(16.5 \%)$ and bilateral in $120(52.2 \%)$. Table 1 presents the frequency distribution of mandibular third molar impaction in males and females and different age groups. The difference between males and females in frequency of bilateral and unilateral impaction was not significant $(\mathrm{p}=0.864)$, but a significant difference was observed with different age groups ( $\mathrm{p}=0.044)$. Only the 50-58-year-olds had significant differences with other age groups in terms of anatomical side of mandibular third molar impaction $(\mathrm{p}<0.05)$.

Table 1. Impaction distribution according to side.

\begin{tabular}{lcccc}
\multicolumn{1}{c}{ Variables } & $\begin{array}{c}\text { Right } \\
\mathrm{N}(\%)\end{array}$ & $\begin{array}{c}\text { Side } \\
\mathrm{N}(\%)\end{array}$ & $\begin{array}{c}\text { Bilateral } \\
\mathrm{N}(\%)\end{array}$ & p-value \\
\hline Gender & $27(29.3)$ & $16(17.4)$ & $49(53.3)$ & 0.864 \\
$\quad$ Male & $45(32.6)$ & $22(15.9)$ & $71(51.4)$ & \\
Female & & & & \\
Age Group & $29(28.2)$ & $15(14.6)$ & $59(57.3)$ & 0.044 \\
18-30 Years & $27(31.0)$ & $14(16.1)$ & $46(52.9)$ & \\
31-40 Years & $13(43.3)$ & $4(13.3)$ & $13(43.3)$ & \\
41-50 Years & $3(30.0)$ & $5(50.0)$ & $2(20.0)$ & \\
$50-58$ Years & &
\end{tabular}

Table 2 presents the frequency distribution of level of mandibular third molar impaction in the right and left sides. Level $\mathrm{C}$ was the most common depth of impaction in both the right (40.1\%) and left (40.5\%) sides. There was no association between the side and the impaction depth $(\mathrm{p}=0.651)$.

Table 2. Frequency distribution of the level of impaction according to the side.

\begin{tabular}{|c|c|c|c|c|c|}
\hline \multirow[b]{2}{*}{ Side } & \multicolumn{3}{|c|}{ Impaction Deep } & \multirow[b]{2}{*}{$\begin{array}{l}\text { Total } \\
\text { N (\%) }\end{array}$} & \multirow[b]{2}{*}{ p-value } \\
\hline & $\begin{array}{c}\text { Level A } \\
\mathrm{N}(\%)\end{array}$ & $\begin{array}{l}\text { Level B } \\
\mathrm{N}(\%)\end{array}$ & $\begin{array}{c}\text { Level C } \\
\text { N (\%) }\end{array}$ & & \\
\hline Right & $55(28.6)$ & $60(31.3)$ & $77(40.1)$ & $192(100.0)$ & 0.651 \\
\hline Left & $36(22.8)$ & $58(36.7)$ & $64(40.5)$ & $158(100.0)$ & \\
\hline
\end{tabular}


Table 3 shows the frequency distribution of position of impacted mandibular third molars relative to the mandibular ramus in the right and left sides. Class I was the most common position in both the right $(60.4 \%)$ and left $(67.7 \%)$ sides. No association was observed between side and position $(\mathrm{p}=0.683)$.

Table 3. Frequency distribution of position according to the side.

\begin{tabular}{lccccc}
\multirow{3}{*}{ Side } & Class I & Position & & & Class II \\
& $\mathrm{N}(\%)$ & $\mathrm{N}(\%)$ & Class III & Total & p-value \\
\hline Right & $116(60.4)$ & $56(29.2)$ & $20(10.4)$ & $192(100.0)$ & 0.683 \\
Left & $107(67.7)$ & $36(22.8)$ & $15(9.5)$ & $158(100.0)$ & \\
\hline
\end{tabular}

Table 4 presents the frequency distribution of mandibular third molar angle of impaction in the right and left sides. The most common angle of impaction was mesioangular (35.9\%) and vertical (32.8\%) in the right side and vertical $(34.8 \%)$ and mesioangular $(32.9 \%)$ in the left side. No significant difference were observed between the side and angles of impaction $(\mathrm{p}=0.581)$.

Table 4. Frequency distribution of impaction in the right and left sides.

\begin{tabular}{lcccccccc}
\multirow{2}{*}{ Side } & \multicolumn{9}{c}{ Angle of Impaction } \\
& Vertical & Mesioangular & Horizontal & Distoangular & Buccolingual & Other & Total & p-value \\
& $\mathrm{N}(\%)$ & $\mathrm{N}(\%)$ & $\mathrm{N}(\%)$ & $\mathrm{N}(\%)$ & $\mathrm{N}(\%)$ & $\mathrm{N}(\%)$ & $\mathrm{N}(\%)$ & \\
\hline Right & $63(32.8)$ & $69(35.9)$ & $46(24)$ & $3(1.6)$ & $10(5.2)$ & $1(0.5)$ & $192(100.0)$ & 0.581 \\
Left & $55(34.8)$ & $52(32.9)$ & $41(25.9)$ & $3(1.9)$ & $7(4.4)$ & $0(0.0)$ & $158(100.0)$ & \\
\hline
\end{tabular}

Table 5 shows the frequency distribution of depth of impaction of mandibular third molars in the right and left sides in males and females. In terms of frequency of depth of impaction of mandibular third molars, no association was noted between males and females in the right $(p=0.141)$ or left $(p=0.401)$ sides.

Table 5. Frequency distribution of depth of impaction according to gender.

\begin{tabular}{|c|c|c|c|c|c|c|}
\hline \multirow[b]{2}{*}{ Side } & \multirow[b]{2}{*}{ Gender } & \multicolumn{4}{|c|}{ Impaction Deep } & \multirow[b]{2}{*}{ p-value } \\
\hline & & $\begin{array}{c}\text { Level A } \\
\mathrm{N}(\%)\end{array}$ & $\begin{array}{c}\text { Level B } \\
\text { N (\%) }\end{array}$ & $\begin{array}{c}\text { Level C } \\
\text { N (\%) }\end{array}$ & $\begin{array}{l}\text { Total } \\
\text { N (\%) }\end{array}$ & \\
\hline \multirow[t]{2}{*}{ Right } & Male & $16(21.1)$ & $28(36.8)$ & $32(42.1)$ & $76(100.0)$ & 0.141 \\
\hline & Female & $39(33.6)$ & $32(27.6)$ & $45(38.8)$ & $116(100.0)$ & \\
\hline \multirow[t]{2}{*}{ Left } & Male & $12(18.5)$ & $23(35.4)$ & $30(46.2)$ & $65(100.0)$ & 0.401 \\
\hline & Female & $24(25.8)$ & $35(37.6)$ & $34(36.6)$ & $93(100.0)$ & \\
\hline
\end{tabular}

Table 6 presents the frequency distribution of position of impacted mandibular third molars relative to the ramus in the right and left sides in males and females. No significant difference was noted between males and females in the right side $(\mathrm{p}=0.301)$, but the difference in the left side was statistically significant $(\mathrm{p}=0.002)$.

Table 6. Impaction distribution according to gender and side.

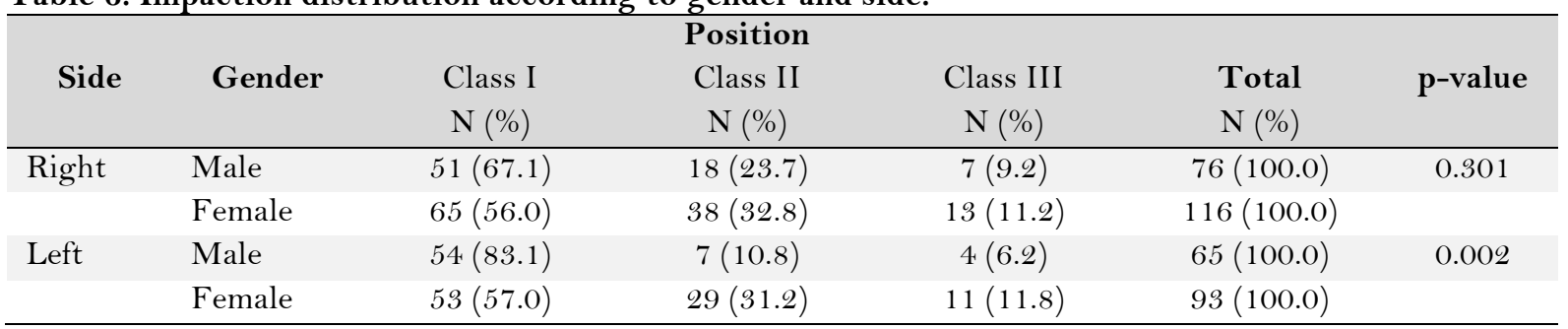


Table 7 shows the frequency distribution of angle of impaction of mandibular third molars in the right and left sides in males and females. No significant difference was noted between males and females in the right $(\mathrm{p}=0.644)$ or left $(\mathrm{p}=0.280)$ side.

Table 7. Frequency distribution of angle of impaction according to side and gender.

\begin{tabular}{llccccccc}
\hline \multirow{2}{*}{ Side } & \multirow{2}{*}{ Gender } & Vertical & Mesioangular & Horizontal & Distoangular & Buccolingual & Others & p-value \\
& & $\mathrm{N}(\%)$ & $\mathrm{N}(\%)$ & $\mathrm{N}(\%)$ & $\mathrm{N}(\%)$ & $\mathrm{N}(\%)$ & $\mathrm{N}(\%)$ & \\
\hline \multirow{2}{*}{ Right } & Males & $23(30.3)$ & $30(39.5)$ & $19(25.0)$ & $0(0.0)$ & $4(5.3)$ & $0(0.0)$ & 0.644 \\
& Females & $40(34.5)$ & $39(33.6)$ & $27(23.3)$ & $3(2.6)$ & $6(5.2)$ & $1(0.9)$ & \\
\multirow{2}{*}{ Left } & Males & $19(29.2)$ & $23(35.4)$ & $21(32.3)$ & $1(1.5)$ & $1(1.5)$ & $0(0.0)$ & 0.280 \\
& Females & $36(38.7)$ & $29(31.2)$ & $20(21.5)$ & $2(2.2)$ & $6(6.5)$ & $0(0.0)$ & \\
\hline
\end{tabular}

\section{Discussion}

Third molar impaction is a common anomaly and the pattern of impaction may be related to the occurrence of disorders, pathologies [6-8] and surgical outcomes [9-11]. Different populations have different patterns of impaction. Thus, this study assessed the patterns of impaction of mandibular third molars in an Iranian subpopulation residing in Kermanshah city.

The frequency of mandibular third molar impaction was 23\% (230 cases out of 1000 radiographs), which was lower than the reported rates in other cities of Iran, including Mashhad (60.78\%) [1] and Kerman $(55 \%)$ [3]. The frequency of mandibular third molar impaction was 84\% in Tanzania [17], 54.3\% in Oman [12], 50.7\% in Turkey [18], 27.3\% in Saudi Arabia [19] and 15.2\% in Eritrea [20].

In the present study, the incidence of mandibular third molar impaction in females was higher than that in males (3:2), which was in agreement with the results of previous studies [1,3,20,21]. Higher frequency in females can be due to differences in growth patterns of males and females. By the time of mandibular third molar eruption, the growth has often ended in females while in males, the growth and development of the jaws continue during eruption of mandibular third molars, and greater space is therefore available for their eruption [3]. However, studies conducted in Turkey [18], Tanzania [17] and Saudi Arabia [14] found no difference between males and females in this respect.

In the present study, bilateral impaction was the most common, followed by the right side impaction. No significant difference was noted in the frequency of impaction between males and females or between different age groups. Similar to our study, previous authors noticed that mandibular third molar impaction was bilateral in most cases [22]. However, in contrast to our study, the highest frequency of impaction was noted in the left side [21] and in the right side [17]. Another authors found no significant difference in the frequency of mandibular third molar impaction in the right and left sides [1,12]. It seems that the frequency of bilateral, right-side and left-side impaction is affected by factors such as genetics and race.

This study showed that level C was the most common depth of impaction in both the right (40.1\%) and left $(40.5 \%)$ sides, which was in agreement with the results observed in Turkish population who also showed that level $\mathrm{C}$ was the most common depth of impaction (61\%) [7]. In contrast to our results, level A was the most common depth of impaction in many previous studies [12,13,20,23]. Previous authors in Iran found that type A was the most common depth of impaction [3], while in Saudi Arabia level B was the most common depth of impaction [1,14]. Differences in level of impaction among different populations can be due to variability in race, patient selection criteria and study population. 
Our results showed that the most common position of impacted third molars relative to the mandibular ramus was Class I in both sides, corroborating previous findings [20], while other studies reported that Class II was the most common position [1,19,23]. Previous study showed that the position of impacted mandibular third molar relative to the mandibular ramus was affected by age [22]. They found that the prevalence of Class I position was zero at 18 years of age, but it increased to $54.9 \%$ in 26 -year-olds.

In our study, the most common angle of impaction was mesioangular and vertical in the right and vertical and mesioangular in the left side. The literature shows that the most common angle was vertical and mesioangular in a study developed in India [13] and vertical in a study conducted in Turkey [7]. In most previous studies, mesioangular impaction was the most common type of impaction $[1,3,12,14,17,18,20-$ 22,24,25]. Previous studies have demonstrated that mesioangular position is associated with the highest risk of caries in the distal surface of mandibular second molars [26-28]. Thus, surgical extraction of impacted mandibular third molars in such cases should be performed to prevent caries in the distal surface of an adjacent second molar tooth.

Our study failed to show any significant association between level or angle of impaction with gender, confirming previous findings [20]. In terms of frequency, no significant difference existed between males and females in terms of position of impacted mandibular third molars relative to the ramus in the right side but this difference was significant in the left side.

One limitation of this study was its retrospective design. Since only radiographs of patients were evaluated, patient complaints regarding impacted third molars could not be evaluated. Second, there was no sample calculation, despite the extensive sample analyzed.

\section{Conclusion}

Mandibular third molar impaction was relatively common in the studied population. The mesioangular, level C and Class I impaction patterns were the most frequent.

\section{Authors' Contributions}

\begin{tabular}{|c|c|c|}
\hline FR & (iD) $0000-0002-9314-7903$ & Conceptualization, Validation. \\
\hline MMI & (iD) $0000-0002-3982-5216$ & Investigation, Formal Analysis, Software. \\
\hline AK & (iD) $0000-0001-5505-7571$ & $\begin{array}{l}\text { Methodology, Writing - Original Draft Preparation and Writing - Review and } \\
\text { Editing. }\end{array}$ \\
\hline AN & (iD) 0000-0003-3974-8385 & Data Curation and Resources. \\
\hline
\end{tabular}

\section{Financial Support}

None.

\section{Conflict of Interest}

The authors declare no conflicts of interest.

\section{References}

[1] Eshghpour M, Nezadi A, Moradi A, Shamsabadi RM, Rezaei NM, Nejat A. Pattern of mandibular third molar impaction: A cross-sectional study in northeast of Iran. Niger J Clin Pract 2014; 17(6):673-7. https://doi.org/10.4103/1119-3077.144376 
[2] Goyal S, Verma P, Raj SS. Radiographic Evaluation of the status of third molars in Sriganganagar population - a digital panoramic study. Malays J Med Sci 2016; 23(6):103-12. https://doi.org/10.21315/mjms2016.23.6.11

[3] Hashemipour MA, Tahmasbi-Arashlow M, Fahimi-Hanzaei F. Incidence of impacted mandibular and maxillary third molars: a radiographic study in a Southeast Iran population. Med Oral Patol Oral Cir Bucal 2013; 18(1):e140-5. https://doi.org/10.4317/medoral.18028

[4] Prajapati VK, Mitra R, Vinayak KM. Pattern of mandibular third molar impaction and its association to caries in mandibular second molar: a clinical variant. Dent Res J 2017; 14(2):137-42.

[5] Wang D, He X, Wang Y, Zhou G, Sun C, Yang L, et al. Topographic relationship between root apex of mesially and horizontally impacted mandibular third molar and lingual plate: cross-sectional analysis using CBCT. Sci Rep 2016; 6:39268.

[6] Srivastava N, Shetty A, Goswami RD, Apparaju V, Bagga V, Kale S. Incidence of distal caries in mandibular second molars due to impacted third molars: nonintervention strategy of asymptomatic third molars causes harm? A retrospective study. Int J Appl Basic Med Res 2017; 7(1):15-9. https://doi.org/10.4103/2229-516X.198505

[7] Yilmaz S, Adisen MZ, Misirlioglu M, Yorubulut S. Assessment of third molar impaction pattern and associated clinical symptoms in a central Anatolian Turkish population. Med Princ Pract 2016; 25(2):169-75. https://doi.org/10.1159/000442416

[8] Gaddipati R, Ramisetty S, Vura N, Kanduri RR, Gunda VK. Impacted mandibular third molars and their influence on mandibular angle and condyle fractures - a retrospective study. J Craniomaxillofac Surg 2014; 42(7):1102-5. https://doi.org/10.1016/j.jcms.2014.01.038

[9] Mahdey HM, Arora S, Wei M. Prevalence and difficulty index associated with the 3(rd) mandibular molar impaction among Malaysian ethnicities: a clinico-radiographic study. J Clin Diagn Res 2015; 9(9):ZC65-8. https://doi.org/10.7860/JCDR/2015/14490.6509

[10] Blondeau F, Daniel NG. Extraction of impacted mandibular third molars: postoperative complications and their risk factors. J Can Dent Assoc 2007; 73(4):325.

[11] Bello SA, Adeyemo WL, Bamgbose BO, Obi EV, Adeyinka AA. Effect of age, impaction types and operative time on inflammatory tissue reactions following lower third molar surgery. Head Face Med 201 1; 7:8.

[12] Al-Anqudi SM, Al-Sudairy S, Al-Hosni A, Al-Maniri A. Prevalence and pattern of third molar impaction: a retrospective study of radiographs in Oman. Sultan Qaboos Univ Med J 2014; 14(3):e388-92.

[13] Kumar Pillai A, Thomas S, Paul G, Singh SK, Moghe S. Incidence of impacted third molars: a radiographic study in People's Hospital, Bhopal, India. J Oral Biol Craniofac Res 2014; 4(2):76-81. https://doi.org/10.1016/j.jobcr.2014.04.001

[14] Hassan AH. Pattern of third molar impaction in a Saudi population. Clin Cosmet Investig Dent 2010; 2:109-13. https://doi.org/10.2147/CCIDEN.S12394

[15] Pell GJ. Impacted mandibular third molars: classification and modified techniques for removal. Dent Digest 1933; 39:330-8.

[16] Winter GB. The Principles of Exodontia as Applied to the Impacted Third Molar. St. Louis: American Medical Book Co.; 1926.

[17] Msagati F, Simon EN, Owibingire S. Pattern of occurrence and treatment of impacted teeth at the Muhimbili National Hospital, Dar es Salaam, Tanzania. BMC Oral Health 2013; 13:37.

[18] Topkara A, Sari Z. Investigation of third molar impaction in Turkish orthodontic patients: prevalence, depth and angular positions. Eur J Dent 2013; 7(Suppl 1):S94-8. https://doi.org/10.4103/1305-7456.119084

[19] El-Khateeb SM, Arnout EA, Hifnawy T. Radiographic assessment of impacted teeth and associated pathosis prevalence. Pattern of occurrence at different ages in Saudi male in Western Saudi Arabia. Saudi Med J 2015; 36(8):973-9. https://doi.org/10.15537/smj.2015.8.12204

[20] Kumar VR, Yadav P, Kahsu E, Girkar F, Chakraborty R. Prevalence and pattern of mandibular third molar impaction in Eritrean population: a retrospective study. J Contemp Dent Pract 2017; 18(2):100-6.

[21] Patel S, Mansuri S, Shaikh F, Shah T. Impacted mandibular third molars: a retrospective study of 1198 cases to assess indications for surgical removal, and correlation with age, sex and type of impaction - a single institutional experience. J Maxillofac Oral Surg 2017; 16(1):79-84. https://doi.org/10.1007/s12663-016-0929-Z

[22] Ryalat S, AlRyalat SA, Kassob Z, Hassona Y, Al-Shayyab MH, Sawair F. Impaction of lower third molars and their association with age: radiological perspectives. BMC Oral Health 2018; 18(1):58.

https://doi.org/10.1186/s12903-018-0519-1

[23] Obiechina AE, Arotiba JT, Fasola AO. Third molar impaction: evaluation of the symptoms and pattern of impaction of mandibular third molar teeth in Nigerians. Odontostomatol Trop 200 1; 24(93):22-5.

[24] Shokri A, Mahmoudzadeh M, Baharvand M, Mortazavi H, Faradmal J, Khajeh S, et al. Position of impacted mandibular third molar in different skeletal facial types: first radiographic evaluation in a group of Iranian patients. Imaging Sci Dent 2014; 44(1):61-5.

[25] Padhye MN, Dabir AV, Girotra CS, Pandhi VH. Pattern of mandibular third molar impaction in the Indian population: a retrospective clinico-radiographic survey. Oral Surg Oral Med Oral Pathol Oral Radiol 2013; 116(3):e161-6. 
[26] Syed KB, Alshahrani FS, Alabsi WS, Alqahtani ZA, Hameed MS, Mustafa AB, et al. Prevalence of distal caries in mandibular second molar due to impacted third molar. J Clin Diagn Res 2017; 11(3):ZC28-ZC30.

[27] Marques J, Montserrat-Bosch M, Figueiredo R, Vilchez-Pérez MA, Valmaseda-Castellón E, Gay-Escoda C. Impacted lower third molars and distal caries in the mandibular second molar. Is prophylactic removal of lower third molars justified? J Clin Exp Dent 2017; 9(6):e794-e798. https://doi.org/10.4317/jced.53919

[28] Srivastava N, Shetty A, Goswami RD, Apparaju V, Bagga V, Kale S. Incidence of distal caries in mandibular second molars due to impacted third molars: Nonintervention strategy of asymptomatic third molars causes harm? A retrospective study. Int J Appl Basic Med Res 2017; 7(1):15-9. https://doi.org/10.4103/2229-516X.198505 